\title{
Practical approach to managing exercise-induced asthma in children and adults
}

\author{
*lain Small, ${ }^{1}$ André Moreira, ${ }^{2}$ Mariana Couto ${ }^{3}$ \\ ${ }^{1}$ General Practitioner, Peterhead Health Centre, NHS Grampian, Scotland, UK \\ 2 Immunology Department, Faculty of Medicine, University of Porto, Porto, Portugal \\ ${ }^{3}$ Allergy, Asthma and Sports Unit, Immunoallergy Department, Centro Hospitalar São João E.P.E., Porto, Portugal
}

\section{A child who is wheezing during school sports lessons}

\section{Clinical scenario}

A 10 year-old girl visits your practice. Her mother is worried about the child's asthma, as it has been causing symptoms every time the girl is doing Physical Education (PE) in school. The mother suggests that "because she is constantly wheezing when she runs, she should have a note from you excusing her from PE". Reviewing the clinical records you realise her asthma has not been reviewed for nearly 18 months. Her current prescription is for fluticasone $100 \mathrm{mcg}$ twice-daily, and salbutamol as required.

This case is interesting, because, on the face of it, it's about a child with asthma made worse by exercise, which is a common phenomenon. However, true exercise-induced asthma, where symptoms only occur in response to physical activity, is relatively uncommon. The mistake to make in this consultation would be to concentrate exclusively on the exercise-induced symptoms whereas, in reality, the situation encompasses many of the important general themes that are current in asthma care across most societies.

Firstly, this is a call to return to the basics of asthma management. If her asthma hasn't been reviewed for 18 months, then she had a diagnosis made when she was no older than $81 / 2$ years of age. Although there is published evidence that spirometry can be accurately assessed from age 5 years onward, ${ }^{1,2}$ in real-life practice objective measurement of lung function using spirometry or peak expiratory flow (PEF) monitoring is difficult in young children. It is worth reviewing how the diagnosis was made - whether she had a positive response to treatment that was sustained over time, and whether withdrawal of her inhaled corticosteroid (ICS) led to a return of symptoms. ${ }^{3}$ In addition, family and personal history of atopy, and the presence of characteristic diurnal symptoms, any deterioration in response to viral, irritant or allergic triggers, and the presence of high pitched rhonchi (or wheeze) on auscultation whilst symptomatic would be useful pointers to a diagnosis of asthma. ${ }^{4-6}$

In addition to reviewing the diagnosis, this consultation is an opportunity to check both her concordance with therapy (cross referencing her statements with her prescription records) and her inhaler technique.

The clinical difficulty now is that our patient is established on regular ICS therapy, making it much more difficult to demonstrate obstructive lung function or diurnal variation, or indeed a fall in PEF in response to triggers. Nonetheless, she should be taught how to use a PEF meter, checking her technique and her understanding of how to document the result, and she should be asked to keep a record for a minimum of two weeks, including not only morning and evening pre-bronchodilator recordings, but also any recordings when symptomatic, particularly relating to exercise. Ideally we should obtain a post-bronchodilator (20-30 minutes) reading following on from an exercise-induced fall in value. A change of $12 \%$ would be significant, ${ }^{7}$ although it is worth noting that a failure to bronchodilate does not exclude asthma. ${ }^{8}$

Another way of establishing exercise-induced symptoms and bronchoconstriction would be to arrange a supervised exercise session (for example in the surgery or pulmonary function laboratory), using either a simple step, or the more complex incremental shuttle walk/run. Ideally, this should take place in a safe environment, where a deterioration in the girl's condition can be monitored and treated. ${ }^{9}$ Breathing cold air (never difficult to arrange in the North East of Scotland!) is likely to result in even more effective bronchoconstriction.

Ninety percent of people with asthma are affected by exercise, and exercise induces asthma symptoms in $35-45 \%$ of people with allergic rhinitis. Even when these two patient groups are excluded, however, there is still a 3-10\% incidence of exercise-induced asthma in the general population. ${ }^{10}$ This distinction is important when it comes to treatment. In a true case of isolated exercise-induced asthma, it is reasonable to prescribe only a short acting $\beta_{2}$-agonist, taken (where possible) in anticipation of the event, or to relieve symptoms. Where more conventional asthma is being triggered by exercise, a formal assessment of asthma control using a validated tool such as the Children's Asthma Control Test ${ }^{11-13}$ will help guide treatment choices. Exercise bronchodilation can then be superimposed onto this regime.

In our patient, there may be a role for giving her a long-acting

* Correspondence: Dr lain Small, Peterhead Health Centre, Links Terrace, Peterhead, Aberdeenshire AB42 2XA, UK

Tel: +44 (0)1779 474841 E-mail: iain.small@nhs.net 
$\beta_{2}$-agonist (LABA) in combination with her ICS, ${ }^{14}$ as this may negate or at least reduce her need for 'anticipatory' reliever therapy. In addition, a 10-year old is likely to be engaging in sporadic unplanned exercise, where pre-exercise bronchodilation is impractical. Leukotreine receptor antagonists (LTRAs) have also been shown to have a role in exercise-induced asthma, ${ }^{15}$ and may help to combat the late bronchoconstriction response so characteristic of this condition.

Onward referral of this child would be unusual, and would only be indicated where there was diagnostic doubt or there was failure to respond to therapy beyond a total daily ICS dose of $800 \mathrm{mcg}$ of beclometasone equivalent. ${ }^{16,17}$

There is of course another dimension to this case. Adolescents with asthma bring with them their own special range of problems. ${ }^{18}$ The role of the school - and in particular her PE teacher - is important, and their understanding of asthma may need to be explored and improved, particularly around access to medication. There are a range of tools that can help to do this, ${ }^{19,20}$ and engaging with schools has been shown to result in improved asthma outcomes for children. ${ }^{21}$ All too often, it remains the case that children have difficulty accessing their medication, a problem that can be amplified on the playing field or playground, with teachers considering that children (particularly girls) are using their asthma and its symptoms as an excuse to avoid games or sports. Children are often reluctant to take their inhalers in public, ${ }^{22}$ and it may be that forms of exercise that are known to be safe (such as swimming ${ }^{23}$ ) could be encouraged. This would help to avoid the withdrawal from exercise that this girl requests and which should be resisted.

\section{An adult who is breathless on walking}

\section{Clinical scenario}

A 52 year-old man has booked an appointment with you. He is worried about his asthma, as it has been causing more symptoms than usual for the last few months. He has been trying to follow your recommendation about losing some weight and keeping fit by walking for 45 minutes a day. He wants to continue his exercise, "now that I have got used to it and have really started to enjoy my daily routine", but he is quite often breathless and wheezing after 15-20 minutes.

You confirm that he has been seeing you regularly for the last year: every 3rd or 4th month.

He is overweight, but not obese and his asthma has been well under control with budesonide 200 mcg twice daily. There have been no new health problems that you know about.

Regular physical exercise and participation in sports are considered to be important components of a healthy life and are recommended for all individuals. However, in patients with asthma, physical exertion is one of many stimuli that can produce episodes of airway obstruction. Physical training improves cardiopulmonary fitness and improves health-related quality of life among people with asthma, ${ }^{24}$
Figure 1. Algorithm of approach and diagnosis of this case-scenario

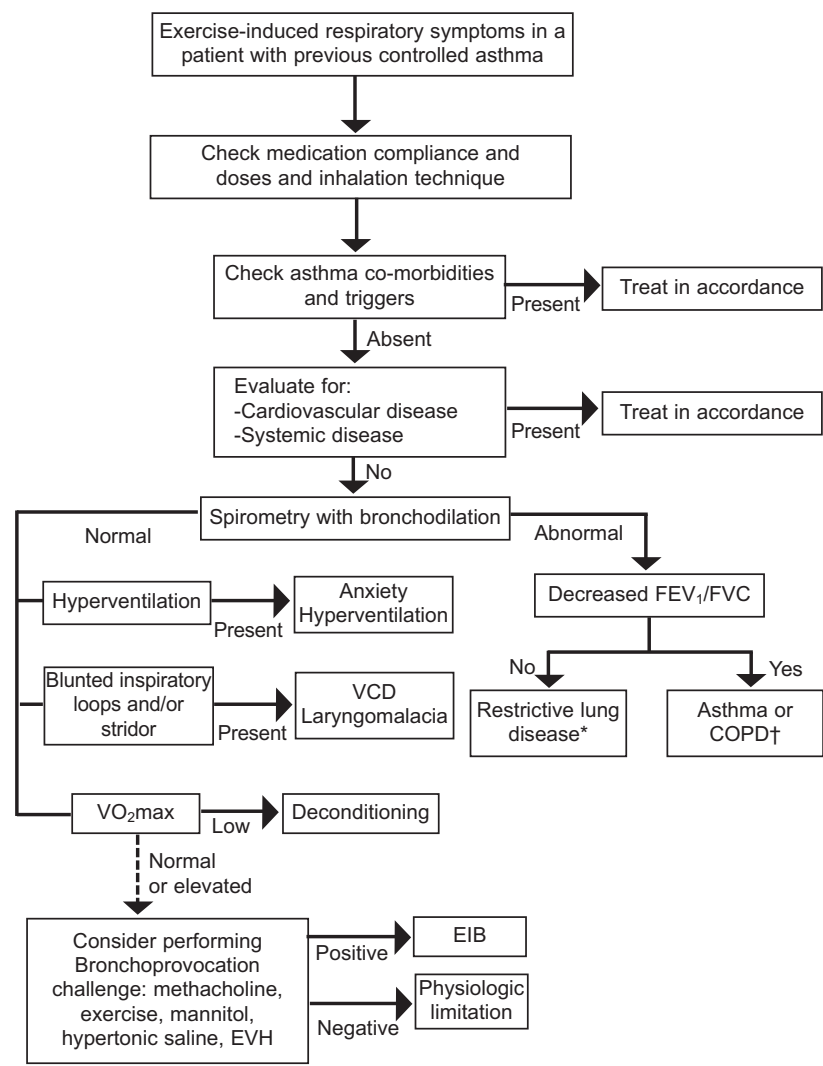

COPD: Chronic obstructive pulmonary disease; EVH: Eucapnic voluntary hyperpnea; $F E V_{1}$ : Forced expiratory volume in the 1st second; FVC: forced vital capacity; VCD: Vocal cord dysfunction; $\mathrm{VO}_{2}$ max: maximal oxygen consumption/uptake.

*Confirm with pletismography for lung volumes and carbon monoxide diffusing capacity (DLCO).

† Differentiate by positive bronchodiltation, history of smoking.

but the worsening of asthma symptoms during exercise can discourage them from playing sports or attempting to keep fit. Therefore, healthcare professionals must make every effort to treat exercise-induced symptoms in order to enable patients to participate in regular exercise without fear of exacerbating symptoms.

\section{Assessment}

The new onset of exercise-induced bronchoconstriction in a patient with previously controlled asthma is a sign of loss of control, ${ }^{25}$ which should prompt consideration of several possibilities. First of all, comorbidities, such as gastro-oesophageal reflux, rhinosinusitis, recent weight gain, cardiovascular conditions, and respiratory infections should be ruled out or treated appropriately. Triggers, including psychological stress, smoking habits, possible allergens and irritants in the sports venue, and changes in occupational environment, must be identified and medication compliance and inhaler technique checked. Also, the presence of other characteristics of uncontrolled asthma should be assessed, such as other daytime symptoms, the need for reliever medication and nocturnal awakenings. Figure 1 presents an algorithm for diagnosing exercise-induced symptoms. 
Table 1. Drugs most frequently used to treat exercise-induced asthma (adapted from Carlsen, ${ }^{37}$ )

\begin{tabular}{lll} 
Drug & Type & Notes \\
\hline Inhaled corticosteroids & Controller & $\begin{array}{l}\text { Presently the most important treatment available. Inhaled steroids with } \\
\text { least side effects, especially lack of adrenal suppression may be particularly } \\
\text { suited for athletes. }\end{array}$ \\
\hline $\begin{array}{ll}\text { Anti-leukotrienes } \\
\text { (Receptor antagonists and 5-LO inhibitors) }\end{array}$ & Controller & $\begin{array}{l}\text { Montelukast protects against exercise-induced asthma without the } \\
\text { development of tolerance. Some patients are non-responders to } \\
\text { anti-leukotrienes, and the effect should be monitored through follow-up. }\end{array}$ \\
\hline Cromones & Controller & $\begin{array}{l}\text { More effective than inhaled anti-cholinergics at attenuating } \\
\text { exercise-induced bronchoconstriction, but less than short-acting } \beta_{2} \text {-agonists }\end{array}$ \\
\hline Inhaled beta2-agonists & Reliever & $\begin{array}{l}\text { Short-acting: Useful for pretreatment before exercise and for reliever } \\
\text { treatment of dyspnoea. Tolerance may develop with regular use. } \\
\end{array}$ \\
& $\begin{array}{l}\text { Long-acting: Useful with uncontrolled exercise-induced asthma both in } \\
\text { schoolchildren and adolescents. Regular use may cause the development of } \\
\text { tolerance. Should not be used without concomitant inhaled corticosteroids. }\end{array}$ \\
\hline Inhaled anti-cholinergics & $\begin{array}{l}\text { May be particularly useful in elite athletes due to possible cholinergic } \\
\text { involvement in pathogenesis. }\end{array}$
\end{tabular}

\section{What is exercise-induced asthma in adults?}

Exercise-induced asthma is defined as lower airway obstruction and respiratory symptoms induced by exercise in patients with underlying asthma. ${ }^{26}$ Physical activity is, in fact, the second leading cause of airway constriction in people with asthma. ${ }^{27}$ However, even in a patient with known asthma, who presents with exercise-induced symptoms, other causes need to be considered. Appropriate management relies on correct and prompt diagnosis (see Figure 1).

\section{How to diagnose exercise-induced asthma in adults?}

Exercise-induced asthma causes dyspnoea (a sensation of discomfort when breathing) which typically develops 5-10 mins after exercise (it rarely occurs during exercise), increased effort or work to breathe, chest tightness, shortness of breath, air hunger, wheezing, or cough. It is, in fact, uncommon in subjects who complain of exerciseinduced dyspnoea. ${ }^{28}$ In the specific case of our clinical scenario, it is important to bear in mind that exercise-induced dyspnoea is very common in overweight/obese patients, ${ }^{29-31}$ and asthma is more difficult to control in this population. ${ }^{25}$

However, the diagnosis of exercise-induced asthma cannot be determined accurately on the basis of self-reported symptoms without objective lung function tests, and therefore confirmation with standardised testing using spirometry with bronchodilation and/or bronchial challenges is strongly recommended.

\section{How to treat? What drug treatment (if any) would you recommend?}

When only intermittent symptoms are present, as-needed reliever medication is suitable. As monotherapy, however, this option should be reserved for patients with occasional daytime symptoms of short duration only related to exercise. ${ }^{25}$ Short-acting $\beta_{2}$-agonists are effective in reversing exercise-induced asthma. Their efficacy is optimal approximately 20 minutes after inhalation and wanes within a few hours. They are also used pre-exercise for prevention.

The primary strategy for managing exercise-induced asthma is to prevent it, and prophylaxis includes not only premedication but also some non-pharmacological interventions, including allergen avoidance when possible. Warm-up of 10 to 15 minutes, including stretching exercises with an objective of reaching $50 \%$ to $60 \%$ of maximum heart rate, should be encouraged, as well as cool-down exercises. This strategy may be helpful in preventing or minimising exercise-induced symptoms. ${ }^{32}$ Exercise-induced asthma may occur in any climatic condition, but it is more common when the patient is breathing dry, cold air than in hot, humid climates. ${ }^{25}$ For exercising in cold air, a mask that facilitates warming of inhaled air can be used. Breathing through the nose may allow humidifying and warming of cool dry air, which raises the importance of treating concomitant rhinitis. Though patients with asthma should not be limited in the sports they choose, selecting a sport based on its low asthmagenic potential may decrease symptoms. ${ }^{33}$

According to GINA guidelines, the presence of symptoms with exercise is a marker of poor asthma control indicating a need for additional controller medications such as inhaled corticosteroids or anti-leukotrienes. ${ }^{25}$ Table 1 summarises currently available drugs for exercise-induced asthma.

For the patient in this particular case-scenario, who was already on ICS, the strategy could be to increase the dose, or add a LABA, or add an LTRA. The latter two drugs have proven effect in preventing exercise-induced asthma and montelukast also improves rhinitis. Underlying rhinitis should be assessed and treated, ${ }^{34}$ including allergen avoidance when possible, pharmcotherapy and potentially immunotherapy in patients with specific allergies. ${ }^{25}$ If treatment fails, the diagnosis should be reconsidered.

\section{When should we consider referral for specialist advice?}

Patients with difficult to control exercise-induced asthma, those performing sports at elite level of competition and those in whom the diagnosis is doubtful should be referred to a specialist. At any time, attention should be paid to the World Anti-doping Agency list of prohibited substances when prescribing drugs for patients within a competing level of sport. ${ }^{35}$ Also, the incorrect use of LABAs without ICS must be avoided at all times, a situation that has been 
highlighted recently as a matter of concern in athletes. ${ }^{36}$

Handling editor Jaime Correia de Sousa

Conflicts of interest is has received honoraria and support to attend international conferences from Almiral, AstraZeneca, Boehringer-Ingelheim, Chiesi, GSK, NAPP, Novartis, Orion. MC and AM declare that they have no conflicts of interest in relation to this article.

\section{References}

1. Bacharier LB, Strunk RC, Mauger D, White D, Lemanske Jr RF, Sorkness CA Classifying asthma severity in children: Mismatch between symptoms, medication use, and lung function. Am J Respir Crit Care Med 2004;170:426-32 http://dx.doi.org/10.1164/rccm.200308-11780C

2. Brouwer AFJ, Roorda RJ, Brand PLP. Home spirometry and asthma severity in children. Eur Respir J 2006;28:1131-7. http://dx.doi.org/10.1183/09031936.06.00118205

3. Bush A. Diagnosis of asthma in children under 5. Prim Care Resp J 2007;16:7-15. http://dx.doi.org/10.3132/pcrj.2007.00001

4. Castro-Rodriguez JA, Holberg CJ, Wright AL, Martinez FD. A clinical index to define risk of asthma in young children with recurrent wheezing. Am J Respir Crit Care Med 2000;162:1403-06.

5. Ly NP, Gold DR, Weiss ST, Celedon JC. Recurrent wheeze in early childhood and asthma among children at risk for atopy. Pediatrics 2006;117:e1132-8 http://dx.doi.org/10.1542/peds.2005-2271

6. Kurukulaaratchy RJ, Matthews S, Holgate ST, Arshad SH. Predicting persistent disease among children who wheeze during early life. Eur Respir J 2003;22:767-71. http://dx.doi.org/10.1183/09031936.03.00005903

7. Pellegrino R, Viegi $G$, Brusasco $V$, et al. Interpretative strategies for lung function tests. Eur Respir J 2005;26:948-68. http://dx.doi.org/10.1183/ 09031936.05.00035205

8. Dundas I, Chan EY, Bridge PD, McKenzie SA. Diagnostic accuracy of bronchodilator responsiveness in wheezy children. Thorax 2005;60:13-16. http://dx.doi.org/ 10.1136/thx.2004.029934

9. Abu-Hasan M, Tannous B, Weinberger M. Exercise-induced dyspnea in children and adolescents: if not asthma then what? Ann Allergy Asthma Immunol 2005;94:36671. http://dx.doi.org/10.1016/S1081-1206(10)60989-1

10. Hough DO, Dec KL. Exercise-induced asthma and anaphylaxis. Sports Med 1994;18:162-72. http://dx.doi.org/10.2165/00007256-199418030-00003

11. Juniper EF, Bousquet J, Abetz L, Bateman ED. Identifying ,well-controlled' and 'not well-controlled' asthma using the Asthma Control Questionnaire. Respir Med 2006;100:616-21. http://dx.doi.org/10.1016/..rmed.2005.08.012

12. Juniper EF, O'Byrne PM, Guyatt GH, Ferrie PJ, King DR. Development ?and validation of a questionnaire to measure asthma control. Eur Respir J 1999;14:902-07. http://dx.doi.org/10.1034//.1399-3003.1999.14d29.x

13. Juniper EF, Svensson K, Mork AC, Stahl E. Measurement properties and interpretation of three shortened versions of the asthma control questionnaire. Respir Med 2005;99:553-8. http://dx.doi.org/10.1016/j.rmed.2004.10.008

14. Medicines and Healthcare products Regulatory Agency. Long-acting b2 agonists for asthma: review. 2008. Available from: http://www.mhra.gov.uk/ \%20Safetyinformation/DrugSafetyUpdate/CON084710 (accessed December 2012)

15. Weiler JM, Anderson SD, Randolph C for the Joint Task Force on Practice Parameters, representing the American Academy of Allergy, Asthma and Immunology; the American College of Allergy, Asthma and Immunology; and the Joint Council of Allergy, Asthma and Immunology. Pathogenesis, prevalence, diagnosis and management of exercise induced bronchoconstriction; a practice parameter. Available from http://www.aaaai.org/Aaaai/media/MediaLibrary/ PDF\%20Documents/Practice \% 20and \%20Parameters/Exercise-inducedbronchoconstriction-2011.pdf (accessed December 2012)

16. NHS Quality Improvement Scotland. Asthma services for children and young people clinical standards, 2007. http://www.healthcareimprovementscotland.org/ previous_resources/standards/asthma_services_for_children_a.aspx (accessed December 2012)

17. Haughney J, Small I, Davison H, Kohli HS. Standards for children with asthma in Scotland. Prim Care Resp J 2007;16:205-06. http://dx.doi.org/10.3132/ pcrj.2007.00057
18. Stearn R. Asthma in Adolescents. Opinion sheet 48. 2011 Available from http://www.pcrs-uk.org/opinions/os48_asthma_adol.pdf (accessed December 2012)

19. Forrest J, Beaton L. A study guide on Children's Health Scottish Executive Education Department 2002. Available from http://www.scotland.gov.uk/Publications/ 2002/07/15075/8616 (accessed December 2012)

20. Asthma UK. Out there and Active Available from http://www.asthma.org.uk/aboutasthma/living-with-asthma/out-there-active-campaign/ (accessed December 2012)

21. Henry RL, Lough S, Mellis C. National policy on asthma management for schools. J Paediatr Child Health 2006:42:491-5. http://dx.doi.org/10.1111/j.14401754.2006.00928.x

22. Cordina M, McElnay JC, Hughes CM, Fenech AG. Health-related issues of importance to school children with asthma - a qualitative study. J Soc Adm Pharm 2002;19:16269.

23. Font Ribera L, Villanueva CM, Nieuwenhuijsen MJ, Zock J-P, Kogevinas M, Henderson J. Swimming Pool Attendance, Asthma, Allergies, and Lung Function in the Avon Longitudinal Study of Parents and Children Cohort. Am J Respir Crit Care Med 2011;183:582-8. http://dx.doi.org/10.1164/rccm.201005-07610C

24. Chandratilleke MG, Carson KV, Picot J, Brinn MP, Esterman AJ, Smith BJ. Physical training for asthma. Cochrane Database Syst Rev 2012;5:CD001116.

25. Global Initiative for Asthma (GINA). Global Strategy for Asthma Management and Prevention. 2011; Available from: http://www.ginasthma.org/ (accessed December 2012)

26. Bousquet J, Clark T, Hurd S, et al. GINA guidelines on asthma and beyond. Allergy 2007;62:102-12. http://dx.doi.org/10.1111/j.1398-9995.2006.01305.x

27. McFadden Jr ER. Approach to the Patient with Exercise-Induced Airway Narrowing. In: Adkinson Jr NF YJ BW, et al, editor. Adkinson: Middleton's Allergy: Principles and Practice. 7th ed. Philadelphia: Mosby; 2008

28. Weiss P, Rundell KW. Imitators of exercise-induced bronchoconstriction. Allergy Asthma Clin Immunol 2009;5:7. http://dx.doi.org/10.1186/1710-1492-5-7

29. Gibson GJ. Obesity, respiratory function and breathlessness. Thorax 2000;55 Suppl 1:S41-4. http://dx.doi.org/10.1136/thorax.55.suppl_1.S41

30. Babb TG, Ranasinghe KG, Comeau LA, Semon TL, Schwartz B. Dyspnea on exertion in obese women: association with an increased oxygen cost of breathing. Am J Respir Crit Care Med 2008;178:116-23. http://dx.doi.org/10.1164/rccm.200706$8750 \mathrm{C}$

31. Sin $D D$, Jones RL, Man SF. Obesity is a risk factor for dyspnea but not for airflow obstruction. Arch Intern Med 2002;162:1477-81. http://dx.doi.org/10.1001/ archinte.162.13.1477

32. Couto M, Moreira A, Delgado L. Diagnosis and treatment of asthma in athletes Breathe 2012;8:286-96

33. Weiler J, Bonini S, Coifman R, et al. American Academy of Allergy, Asthma \& Immunology Work Group report: exercise-induced asthma. J Allergy Clin Immunol 2007;119:1349-58. http://dx.doi.org/10.1016/j.jaci.2007.02.041

34. Silva D, Moreira A, Delgado L. Allergic Rhinitis and Sports. In: Kowalski ML, editor Allergic Rhinitis: InTech; 2012

35. World Anti-doping Agency. List of Prohibited List of Prohibited Substances and Methods. Updated annually and available from http://www.wada-ama.org/ (accessed January 2013)

36. Couto M, Horta L, Delgado L, Capão-Filipe M, Moreira A. Impact of Changes in AntiDoping Regulations (WADA Guidelines) on Asthma Care in Athletes. Clin J Sport Med 2012; [Epub ahead of print]

37. Carlsen K.-H., Carlsen K. L. Physical exercise, training and sports in asthmatic children and adolescents. European Respiratory Society Monographs 2012;56:49-58. http://dx.doi.org/10.1183/1025448x.10016210

Commissioned article; externally peer-reviewed; received 16th December 2012; accepted 26th January 2013; online 25th February 2013

() 2013 Primary Care Respiratory Society UK. All rights reserved.

I Small et al. Prim Care Respir I 2013;22(1):126-129.

http://dx.doi.org/10.4104/pcrj.2013.00026

Available online at http://www.thepcrj.org 